\title{
COVID-19 early stage social acceptance of entry restrictions for international tourists to Japan
}

\author{
Thomas Jones and Minh-Hoang Nguyen
}

Thomas Jones is based at the Ritsumeikan Asia Pacific University, Beppu, Japan. Minh-Hoang Nguyen is based at the Centre for Interdisciplinary Social Research, Phenikaa University, Hanoi, Vietnam.

Received 15 November 2020 Revised 28 February 2021 10 April 2021

Accepted 5 May 2021

(c) Thomas Jones and Minh-Hoang Nguyen.

Published in Journal of Tourism Futures. Published by Emerald Publishing Limited. This article is published under the Creative Commons Attribution (CC BY 4.0) licence. Anyone may reproduce, distribute, translate and create derivative works of this article (for both commercial and non-commercial purposes), subject to full attribution to the original publication and authors. The full terms of this licence may be seen at http://creativecommons.org/licences/by/4.0/ legalcode

Thank you to the survey respondents, Kujyu Forest Park Skiing Ground and the Japanese Ministry of Environment.

\begin{abstract}
Purpose - Different countries have responded to the pandemic with distinct domestic and international travel restrictions. The purpose of this paper is to investigate the stringency of the coronavirus disease 2019 (COVID-19) countermeasures in Japan against their G20 cohorts. Primary data were monitored at a ski resort in Kyushu regarding the social acceptance of initial COVID-19 countermeasures, ranging from hygiene and local "lockdowns" to border control measures.

Design/methodology/approach - The stringency of the COVID-19 countermeasures was examined using data from the Oxford COVID-19 Government Response Tracker (OxCGRT) and triangulated with the early stage social acceptance of survey respondents in Aso Kuju National Park in February 2020 that consisted of 165 valid Japanese language questionnaires.

Findings - An one-way analysis of variance (ANOVA) identified significant differences in social acceptance for countermeasures, with more-concerned respondents agreeing more strongly with "lowtech" health protocols, such as washing hands $(\mathrm{M}=3.7)$ or wearing a mask (3.4). More concerned visitors were significantly more likely to modify their travel plans (2.9) or cancel their trip altogether (2.7). Male day trippers were less likely to be concerned by the COVID-19 pandemic.

Originality/value - This paper's originality is derived from a triangulation of the stringency of Japan's initial COVID-19 countermeasures via a combination of comparison with G20 cohorts and social acceptance of domestic snowboarders and skiers. Moreover, by shining a light on the trade-off between public health and human rights, the paper provides a current review of the ethical dimension of a travel restriction debate that is often overlooked in the ongoing pandemic.
\end{abstract}

Keywords Travel restrictions, COVID-19 counter-measures, Coronavirus, International tourists, Domestic perceptions, Stringency, Social acceptance, Human rights

Paper type Research paper

\section{Introduction}

Following the novel coronavirus disease 2019 (COVID-19) outbreak that was first identified in Wuhan, China, in late 2019, the exponential growth in coronavirus cases has had drastic ramifications for global tourism. However, different countries have been affected differently at different stages of the pandemic and responded with distinct domestic and international restrictions. For the latter, international travel restrictions and border control procedures have been tightened to an unprecedented extent, including a combination of total travel bans or heightened restrictions that combine entry screening, quarantine and compulsory or self-isolation provisions (Anzai et al., 2020). The World Health Organization (WHO) initially did not recommend any travel restrictions at the outbreak of the pandemic, with a joint statement by the UNWTO (the World Tourism Organization) and WHO calling instead for "responsibility and coordination" (WHO, 2020). However, national governments have been forced to implement progressively stricter COVID-19 countermeasures that range from social distancing to "lockdown" stay at home requirements. Questions have subsequently 
arisen over the effectiveness of "lockdown" responses that vary according to the timing and the stringency of the government-imposed measures (Hale et al., 2020).

A concurrent trade-off has occurred due to the de facto prioritization of human health over human rights as "widespread restrictions of varying degrees have been placed on individuals, groups, communities, cities or countries" (Chia and Oyeniran, 2020). Age is one relevant variable as debate is crucial for Millennials and Generation Z that stand to lose more from socio-economic hardship. Due to the comparatively smaller risk of severe COVID-19 complications, younger generations may be less likely to heed public health warnings (Gharzai et al., 2020). Moreover, Zenker and Kock (2020) recently called for further studies to test the connection between the pandemic and public reactions, like ethnocentrism, xenophobia and perceived crowding. Using the case study of onset-era Japan, we investigate the social acceptance of seven COVID-19 countermeasures ranging from "low-tech" hygiene protocols, such as washing hands or wearing a mask, through changing or cancelling their own travel plans, to restrictions on international travel. Apart from age, social acceptance predictors could include such variables as gender and nationality not least due to the distinct policies pursued by different countries. Consideration of "collectivist" East Asian culture (An and Tang, 2020) can help evaluate the effectiveness of Japan's national policy in an international context.

This paper is divided into six sections. First, we analysed data from the Oxford COVID-19 Government Response Tracker (OxCGRT) to position the Japanese governments' stringency policies against their G20 cohorts since the outbreak of the pandemic. The global tourism sector has been severely impacted by the COVID-19 pandemic, with travel restrictions continuing to keep many parts of the world in "lockdown" and limit travellers' rights to cross borders or visit certain tourist destinations. The next section tracks the early stage COVID-19 perceptions of young Japanese visitors to a ski resort. Primary data regarding travel restrictions were collected in February 2020 from a sample of skier and snowboarder respondents. Finally, we discussed the ramifications for public health and human rights in light of the subsequent easing of entry restrictions for international travellers to Japan.

\section{The stringency of COVID-19 countermeasures in Japan compared with the G20 cohorts}

The OxCGRT is a "cross-national, cross-temporal measure" of government responses since the outbreak that 'tracks governments' policies and interventions across a standardized series of indicators and creates a suite of composites indices to measure the extent of these responses" (Hale et al., 2020). A total of 18 indicators from 150 countries are currently being collected by a team of over 100 Oxford staff students and alumni and compiled in an openly-available online database (Hale et al., 2020).

Our research focused on interventions most directly related to the tourism sector by selecting three ordinal OxCGRT indicators: stay at home requirements (C6), restrictions on internal movement (C7) and restrictions on international travel (C8) (Hale et al., 2020). A full list of standardized indicators and the composite indices from which they are drawn is available online at https://github.com/OxCGRT/covid-policy-tracker.

Figure 1.1 compares the OxCGRT stringency index across a G20 median (the orange line) against recorded changes in the Japanese government's response (the blue bars). The stringency index, in turn, is calculated from the simple averages of the nine individual component indicators $(\mathrm{C} 1-\mathrm{C} 8+\mathrm{H} 1)$, the most relevant three of which are displayed here individually in the subsequent charts. After deliberation, three ordinal OxCGRT indicators were selected as the most relevant for the tourism sector: stay at home requirements (C6), restrictions on internal movement (C7) and restrictions on international travel (C8). 


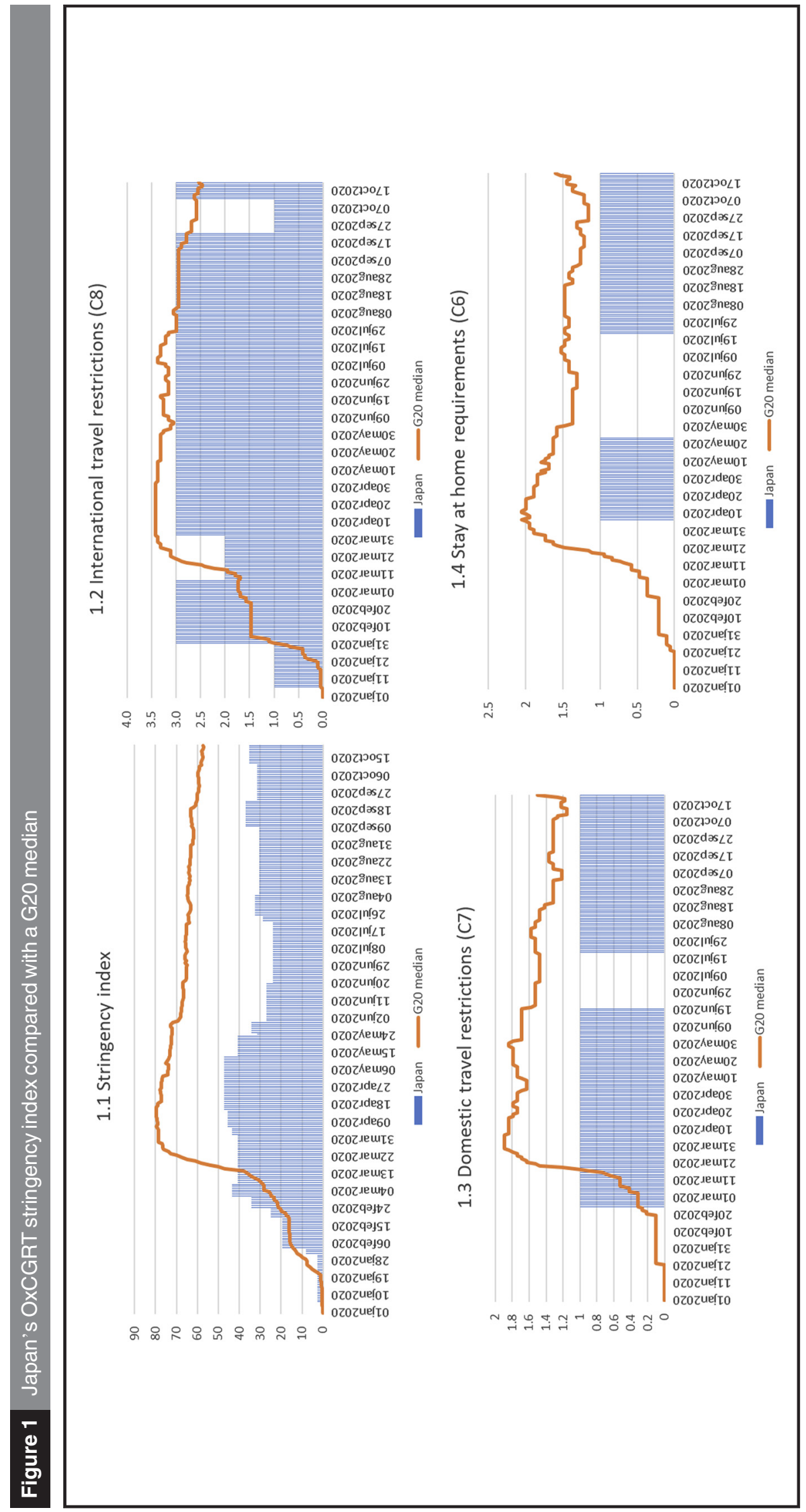

PAGE $324 \mid$ JOURNAL OF TOURISM FUTURES $\mid$ VOL. 7 NO. 32021 
The OxCGRT index from January to October 2020 reveals that Japanese stringency increased slightly sooner than the G20 average (see Figure 1.1), especially due to restrictions on international travel from February onwards (see Figure 1.2). These were briefly relaxed from 09 March to 03 April, when the C8 indicator was raised again to level 3 , apart from a period of level 1 from 24 September to 13 October. In terms of localized restrictions on internal movement within the country (see Figure 1.3), Japan's C7 indicator was raised to level 1 on 25 February, where it remained apart from a period of approximately one month from 21 June to 23 July when restrictions were removed. Generally, this represents a significantly less stringent policy than the G20 medians, likewise the "lockdown"-like stay at home requirements (see Figure 1.4), where Japan's response was later and less stringent than the G20 equivalent. Neither Japan's C6 nor C7 indicator exceeded level 1 on the OxCGRT index. In the months of June and July, local restrictions were lifted altogether, only to be reinstated after an uptick in the number of COVID-19 cases.

\section{Materials and methods}

\subsection{Onset stage survey on the perception of COVID-19 countermeasures}

A visitor survey was conducted in 2020 as part of a project in the Aso Kuju National Park. Located in mountainous Kyushu in Southwest Japan, the Aso caldera and neighbouring Kuju mountain ranges have recently attracted increasing numbers of inbound visitors, so the project's aims had included consideration of marketing management of international visitors in the national park. Covering an area of 72,678 ha, the national park, located on the border of Oita and Kumamoto prefectures, is famous for its scenic landscape and abundant grasslands in four seasons. In the winter, the park is also known as the largest ski resort in Kyushu Japan's southernmost island - in which our survey was implemented (see Figure 2).

\section{Figure 2 Location of study site in Aso Kuju National Park (UNEP-WCMC, 2020)}

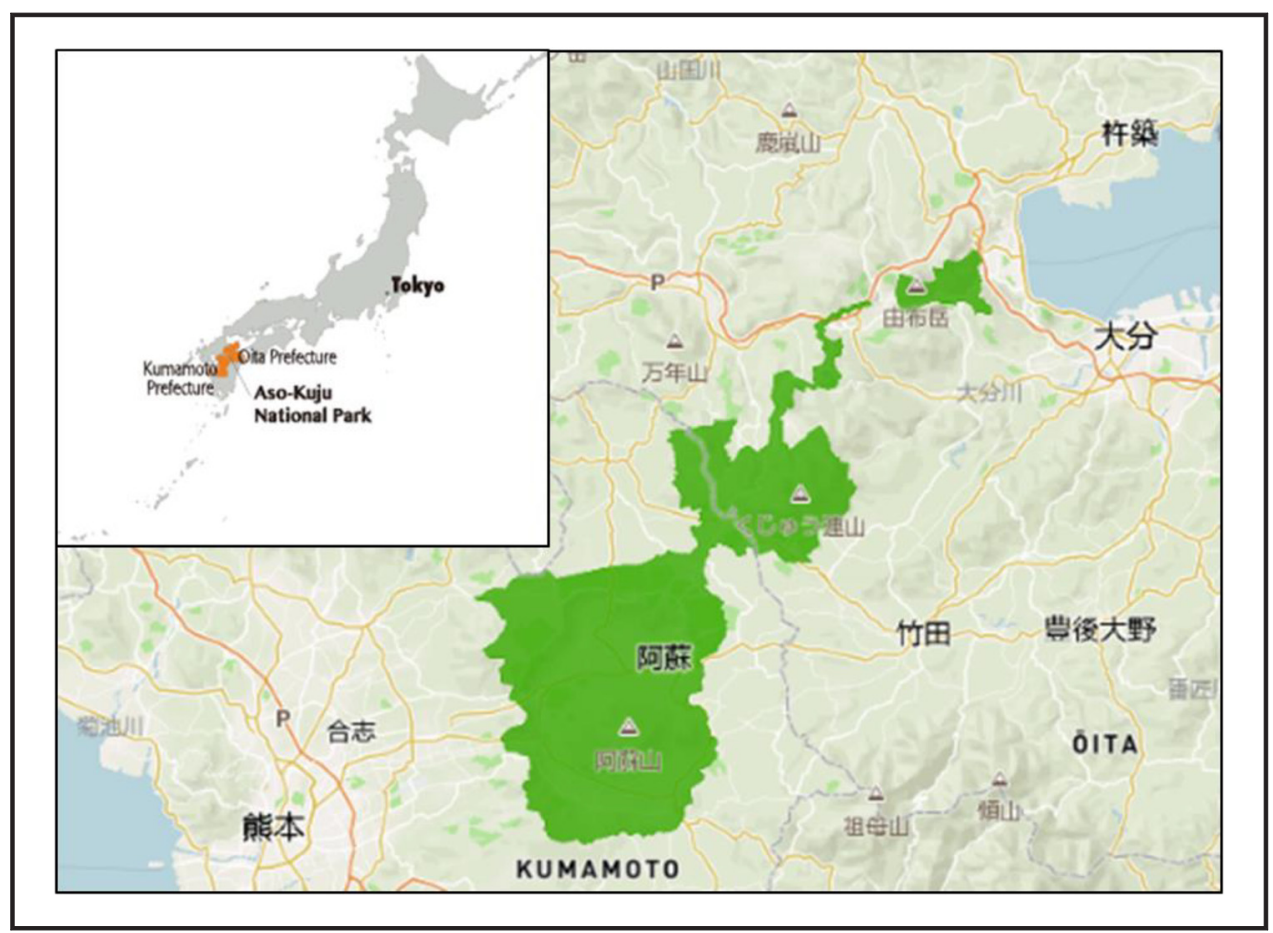


While conducting an in situ multi-lingual questionnaire survey, the onset of the COVID-19 pandemic paralysed the global tourism industry.

The survey's timing coincided with the start of restrictions on international travel into Japan on the 1st February 2020. The media presence was also high due to breaking news of the Diamond Princess cruise ship moored in Yokohama, aboard which over 700 passengers were ultimately diagnosed with COVID-19 (Mallapaty, 2020). Self-administered questionnaires were collected at Kuju Shinrin Koen ski resort by two authors and two other trained data collectors. The survey was conducted at the ski resort's Centre House and Café area, and the visitors were randomly approached. Hence, each respondent had an equal probability of being chosen for the study. The survey collection started at 9:00 am and lasted until the ski resort's closure time for three days in early February (7th, 8th and 9th), including both weekday and weekends. The study period was purposively selected to coincide with the Winter peak season of visitation to Kuju national park. Domestic visitors were approached, and potential respondents underwent a brief explanation in Japanese about the questionnaire's purpose and scope before the questionnaire was provided. In total, 165 valid Japanese language questionnaires were collected.

The on-site intercept survey consisted of four sections: demographic and trip profiles; motivations to visit Kuju national park; evaluation of Kuju national park and their perceptions of COVID-19 travel restrictions. However, in the current study, we focused only on the first and last sections of socio-demographic profiles and opinions about COVID-19. The sociodemographic variables included in this study were gender, age, educational level, travelling with a companion, accommodating at Kuju national park overnight, means of transport and willingness to return (see Table 1). For the section regarding the opinion about COVID-19, a brief explanation of the COVID-19 outbreak's situation was given prior to the questions. After reading the explanation, the visitors were asked about their level of concern towards the COVID-19 outbreak based on a four-point Likert scale ("not at all", "not very concerned", "concerned" and "very concerned"). Later, the respondents were also asked to locate their agreement level on seven COVID-19 prevention methods from the virus based on a fourpoint Likert scale ("strongly disagree", "disagree", "agree" and "strongly agree"). The seven countermeasures were adapted from scanning prevention methods during the 2003 outbreak of SARS (severe acute respiratory syndrome) (Brug et al., 2004).

Descriptive statistics of the questionnaire are summarized in Table 1. Our respondent profile comprised more Japanese males $(n=95)$ than females $(n=72)$. The average age was 34.5 years old, although females were slightly younger (32.8 years). In connection with the younger age, the demographic profile revealed snowboarding to be the dominant attraction $(n=114)$ followed by skiing $(n=40)$ and seven respondents that took part in snowplay (a kids' park set up for children to try sledging, etc.). A majority had completed a university degree $(n=95)$, although females with a degree $(64 \%)$ were significantly higher than males (53\%). The private car was the dominant mode of transport to the national park ( $n=143$ ), and $78 \%$ were on a day trip. Visitors were motivated by the opportunity to "enjoy time with family or friends" (3.5) and "share travel experiences after returning home" (3.3). Still, the motivation data were explored more thoroughly in a separate paper (※reference withheld as currently under review). A total of $73 \%$ were more concerned by the COVID-19, including $22 \%$ who were very concerned and $51 \%$ who were somewhat concerned. However, the majority of females (61\%) were somewhat concerned, a point we will return to later on in the analysis.

Regarding COVID-19 countermeasures, respondents strongly agreed with basic health protocols, such as washing hands regularly ( $M=3.6$ on a four-point Likert scale) or wearing a mask (3.3). However, social acceptance declined when respondents were asked to consider changing their travel plans (2.8) or cancel their trip altogether (2.5). Agreement levels declined notably when asked about the recent policy to restrict all foreign nationals' entry into Japan (2.2). 
Table 1 Respondents' descriptive statistics by gender

\begin{tabular}{|c|c|c|c|c|c|c|c|}
\hline & \multirow[b]{2}{*}{ Level } & \multicolumn{2}{|c|}{ Total $(\mathrm{N}=165)$} & \multicolumn{2}{|c|}{ Male $(\mathbb{N}=93)$} & \multicolumn{2}{|c|}{ Female $(\mathrm{N}=72)$} \\
\hline & & Frequency & (\%) & Frequency & (\%) & Frequency & (\%) \\
\hline \multicolumn{2}{|l|}{ Average age } & \multicolumn{2}{|l|}{34.51} & \multicolumn{2}{|l|}{35.84} & \multicolumn{2}{|l|}{32.79} \\
\hline \multirow[t]{4}{*}{ Highest level of completed education } & Grad. school & 4 & 2.42 & 2 & 2.15 & 2 & 2.78 \\
\hline & University & 95 & 57.58 & 49 & 52.69 & 46 & 63.89 \\
\hline & High school & 55 & 33.33 & 33 & 35.48 & 22 & 30.56 \\
\hline & Secondary school & 4 & 2.42 & 4 & 4.30 & 0 & 0.00 \\
\hline \multirow[t]{4}{*}{ Means of transport } & Primary school & 3 & 1.82 & 2 & 2.15 & 1 & 1.39 \\
\hline & Private vehicle & 143 & 86.67 & 81 & 87.10 & 62 & 86.11 \\
\hline & Rental vehicle & 9 & 5.46 & 4 & 4.30 & 5 & 6.94 \\
\hline & Others (public transport/tour bus) & 12 & 7.27 & 8 & 8.60 & 4 & 5.33 \\
\hline \multirow[t]{3}{*}{ Length of stay } & Day trip & 128 & 77.58 & 72 & 77.42 & 56 & 77.78 \\
\hline & One night & 31 & 18.79 & 16 & 17.20 & 15 & 20.83 \\
\hline & Two nights or more & 3 & 1.82 & 3 & 3.23 & 0 & 0.00 \\
\hline \multirow[t]{3}{*}{ Activities } & Ski & 40 & 24.24 & 25 & 26.88 & 15 & 20.83 \\
\hline & Snowboard & 114 & 69.09 & 61 & 65.59 & 53 & 73.61 \\
\hline & Snowplay & 7 & 4.24 & 5 & 5.38 & 2 & 2.78 \\
\hline \multirow[t]{2}{*}{ Less concerned } & Unconcerned & 12 & 7.32 & 12 & 12.90 & 0 & 0.00 \\
\hline & Not at all concerned & 32 & 19.51 & 20 & 21.51 & 12 & 16.90 \\
\hline \multirow[t]{2}{*}{ More concerned } & Concerned & 84 & 51.22 & 41 & 44.09 & 43 & 60.56 \\
\hline & Very concerned & 36 & 21.95 & 20 & 21.51 & 16 & 22.54 \\
\hline \multirow[t]{2}{*}{ COVID-19 concern } & More concerned & 120 & 72.73 & 61 & 65.59 & 59 & 81.94 \\
\hline & Less concerned & 44 & 26.67 & 32 & 34.41 & 12 & 16.67 \\
\hline \multicolumn{8}{|c|}{ Social acceptance of COVID-19 countermeasures ( 1 = completely disagree; $4=$ completely agree $)$} \\
\hline \multicolumn{4}{|l|}{ Wearing a mask } & \multicolumn{2}{|l|}{3.15} & \multicolumn{2}{|c|}{3.48} \\
\hline \multicolumn{2}{|l|}{ Washing hands } & \multicolumn{2}{|c|}{3.62} & \multicolumn{2}{|l|}{3.51} & \multicolumn{2}{|c|}{3.77} \\
\hline \multicolumn{2}{|l|}{ Change own travel plans } & \multicolumn{2}{|c|}{2.75} & \multicolumn{2}{|l|}{2.64} & \multicolumn{2}{|c|}{2.90} \\
\hline \multicolumn{2}{|l|}{ Cancel own travel plans } & \multicolumn{2}{|c|}{2.54} & 2.44 & & 2.66 & \\
\hline Restrict foreign travellers to Kuju & 2.36 & & & 2.27 & & $2.4 \varepsilon$ & \\
\hline Restrict foreigners from high-risk area & 2.85 & & & 2.75 & & 2.97 & \\
\hline Restrict all foreign travellers into Japar & 2.19 & & & 2.09 & & 2.32 & \\
\hline
\end{tabular}

\subsection{Analysis of variance and probability tests}

In this study, we conducted statistical analyses through several steps. First of all, raw data were entered into MS Excel for data curation, treatment and structuring. Missing interval data were treated using the imputation technique, whereas missing categorical data were removed from the analysis (e.g. gender and staying overnight). Specifically, the missing interval data were substituted with the average value of all observations. We also restructured the visitors' level of concern towards the COVID-19 outbreak into a binary dataset for subsequent statistical analysis. The data for "Concerned" respondents were initially collected using a four-point Likert scale, but they were transformed into dichotomous data here for further analysis (see Table 1). Respondents who checked "not at all" or "not concerned" were grouped as "not concerned", and the rest were labelled "concerned".

Next, the MS Excel file was saved as CSV files for further analysis of variance (ANOVA) and generalized linear model (GLM) analysis using the R software (version 4.0.2). While ANOVA was employed to examine the significance of countermeasure differences between concerned and not concerned visitors, GLM analysis was to predict the probability of a visitor's concern towards COVID-19 outbreak ("Concerned") conditional on their gender ("Gender") and length of stay ("Stay"). The GLM approach has some advantages over conventional linear regression. It can deal with diverse types of dependent variables, including binary logistic regression, as used here, without the assumption on residual's normal distribution (PennState, n.d.). 
As all the variables used in our model were binomial or categorical, we selected the binary logistic regression. The binary logistic regression analysis owns several advantages (Vuong, 2015, p. 1). The model includes a predetermined number of variables, showing the significance of each variable more clearly; and 2) the estimated coefficients can be explained directly using empirical probabilities of the events. The z-value and $p$-value imply the statistical significance of the predictor variables, with $p$-value $<0.05$ being the statistical significance level. A detailed explanation of the logistic regression can be found in (PennState, n.d.; Vuong et al., 2018).

\section{Results}

In this section, we present the results of ANOVA and binary logistic regression analyses. We ranked the most commonly-conducted countermeasures by the mean score and used oneway ANOVA to identify the difference in countermeasures favoured by concerned and not concerned visitors (see Table 2). Significant differences emerged between concerned respondents who agreed more strongly with "low-tech" health protocols, such as washing hands regularly $(M=3.7)$ or wearing a mask (3.4). Concerned visitors were significantly more likely to change their travel plans (2.9) or cancel their trip altogether (2.7). Among seven countermeasures, social acceptance levels towards frequently washing hands, using a mask, change and cancellation of own plans were found to contain statistically significant differences between concerned and not concerned segments. Concerned visitors were also more likely to agree with the policy to restrict all foreign visitors from entering Japan (see Figure 3). However, the concern level showed no statistically significant effect on visitors' perceptions regarding this or the other two potential countermeasures to restrict foreign travellers (see Table 2). By gender, female respondents were significantly more likely to agree with measures to wash hands (3.5) and wear a mask (3.8) (see Table 3).

Next, we conducted a GLM analysis to estimate the probability of respondents being "Concerned" by COVID-19 against two predictor variables "Gender" and "Stay". Other variables were also tested but showed no statistical significance. The baseline category of the dependent variable was "Not concerned". The estimated results are shown in Table 3, in which all associations are statistically significant at $5 \%$ ( $p$-value $<0.05)$. "Gender" was negatively associated with the probability of being concerned, whereas the overnight "Stay" variable was positively associated with the probability of being concerned. In other words, male visitors were less likely to be concerned by the COVID-19 pandemic, whereas respondents staying one or more nights in the national park were more likely to be concerned. The empirical results shown in Table 4 can also be rewritten as follows:

$$
\ln \left(\frac{\hat{\pi}_{\text {Concerned }}}{\hat{\pi}_{\text {Not concerned }}}\right)=1.505-1.005 \text { Male }+1.125 \text { One night }
$$

\begin{tabular}{lllccc} 
Table 2 & $\begin{array}{l}\text { ANOVA in agreement with seven countermeasures by more and less concerned } \\
\text { visitors }\end{array}$ \\
Countermeasure & Rank & Median & More concerned & Less concerned & F-value \\
\hline Washing hands & 1 & 3.62 & 3.737 & 3.447 & $10.09^{* * *}$ \\
Wearing a mask & 2 & 3.29 & 3.439 & 3.026 & $8.544^{* * *}$ \\
Restrict foreigners from high-risk areas & 3 & 2.85 & 2.930 & 2.711 & 1.324 \\
Change my travel plans & 4 & 2.76 & 2.947 & 2.368 & $11.700^{* * *}$ \\
Cancel my travel plans & 5 & 2.54 & 2.719 & 2.105 & $12.730^{* * *}$ \\
Restrict foreign travellers to Kuju & 6 & 2.36 & 2.456 & 2.184 & 2.165 \\
Restrict all foreign travellers into Japan & 7 & 2.19 & 2.254 & 2.026 & 1.477 \\
Note: ${ }^{*},{ }^{* *}$ and ${ }^{* * *}$ represent significance level at 10,5 and $1 \%$, respectively & &
\end{tabular}




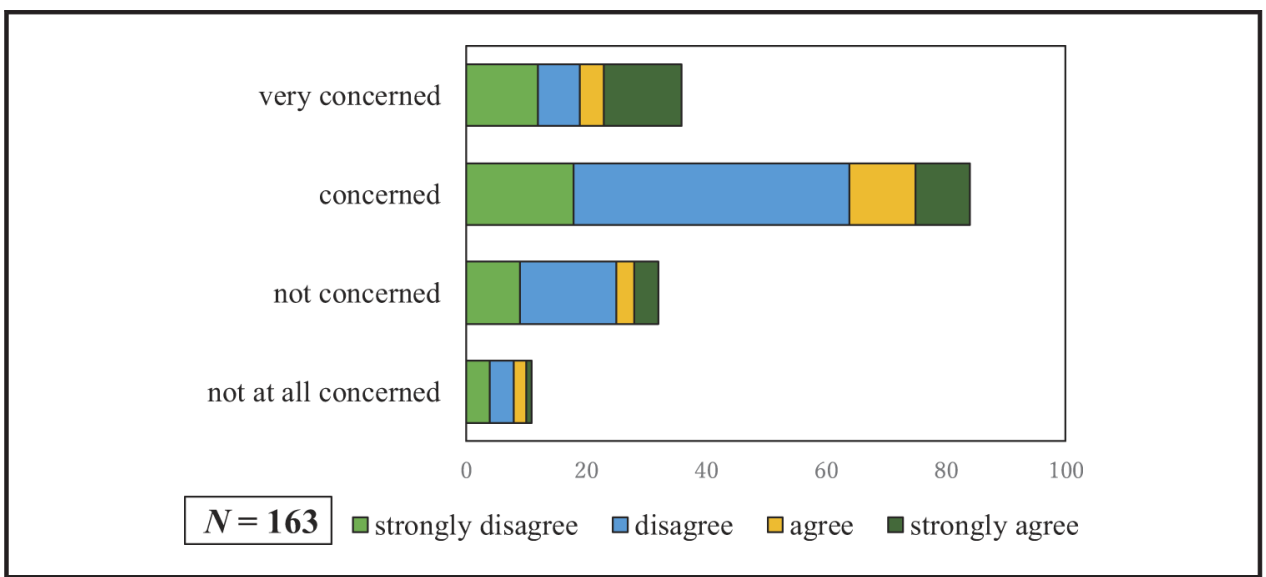

\section{Table 3 ANOVA in agreement with seven countermeasures by gender}

\begin{tabular}{lccccc} 
Countermeasure & Rank & Median & Male & Female & F-value \\
\hline Washing hands & 1 & 3.62 & 3.151 & 3.476 & $6.906^{* *}$ \\
Wearing a mask & 2 & 3.29 & 3.505 & 3.773 & $8.797^{* *}$ \\
Restrict foreigners from high-risk areas & 3 & 2.85 & 2.751 & 2.970 & 1.876 \\
Change my travel plans & 4 & 2.76 & 2.643 & 2.899 & 2.999 \\
Cancel my travel plans & 5 & 2.54 & 2.441 & 2.660 & 2.160 \\
Restrict foreign travellers to Kuju & 6 & 2.36 & 2.273 & 2.478 & 1.775 \\
Restrict all foreign travellers into Japan & 7 & 2.19 & 2.088 & 2.322 & 2.224 \\
Note: *, ** and *** represent significance level at 10,5 and 1\%, respectively & &
\end{tabular}

\section{Table 4 Estimated results of "Concerned" as dependent variable against "Gender" and} "Stay"

\begin{tabular}{lccc} 
& & Gender & Stay \\
& Intercept & Male & One night \\
$\boldsymbol{\beta}_{0}$ & $\boldsymbol{\beta}_{1}$ & $\boldsymbol{\beta}_{2}$ \\
\hline Logit (concerned | not concerned) & $1.505^{* * *}$ & $-1.005^{*}$ & $1.125^{*}$ \\
& {$[4.48]$} & {$[-2.50]$} & {$[2.07]$}
\end{tabular}

Notes: Significance code: "*", "***" and "***" represent statistical significance at 10,5 and $1 \%$, respectively; residual deviance: 170.64 on 158 degree of freedom; null deviance: 182.70 on 160 degrees of freedom; AIC: 176.64 and baseline category: not concerned about the pandemic

Based on the above logit, we can calculate the probability of being concerned amongst visitors who are males and expect to spend one night in Kuju using the following formula:

$$
\hat{\pi}_{\text {Concerned }}=\frac{e^{1.505-1.005+1.125}}{1+e^{1.505-1.005+1.125}}=0.84
$$

From the probabilities estimated from coefficients in Table 4, the contrast of changing probabilities for being concerned according to gender and overnight stay can be illustrated in Figure 4. The probability of concerned female visitors expecting to do a day trip travel is 
Figure 4 Probabilities of "Concerned" upon "Gender" and "Stay"

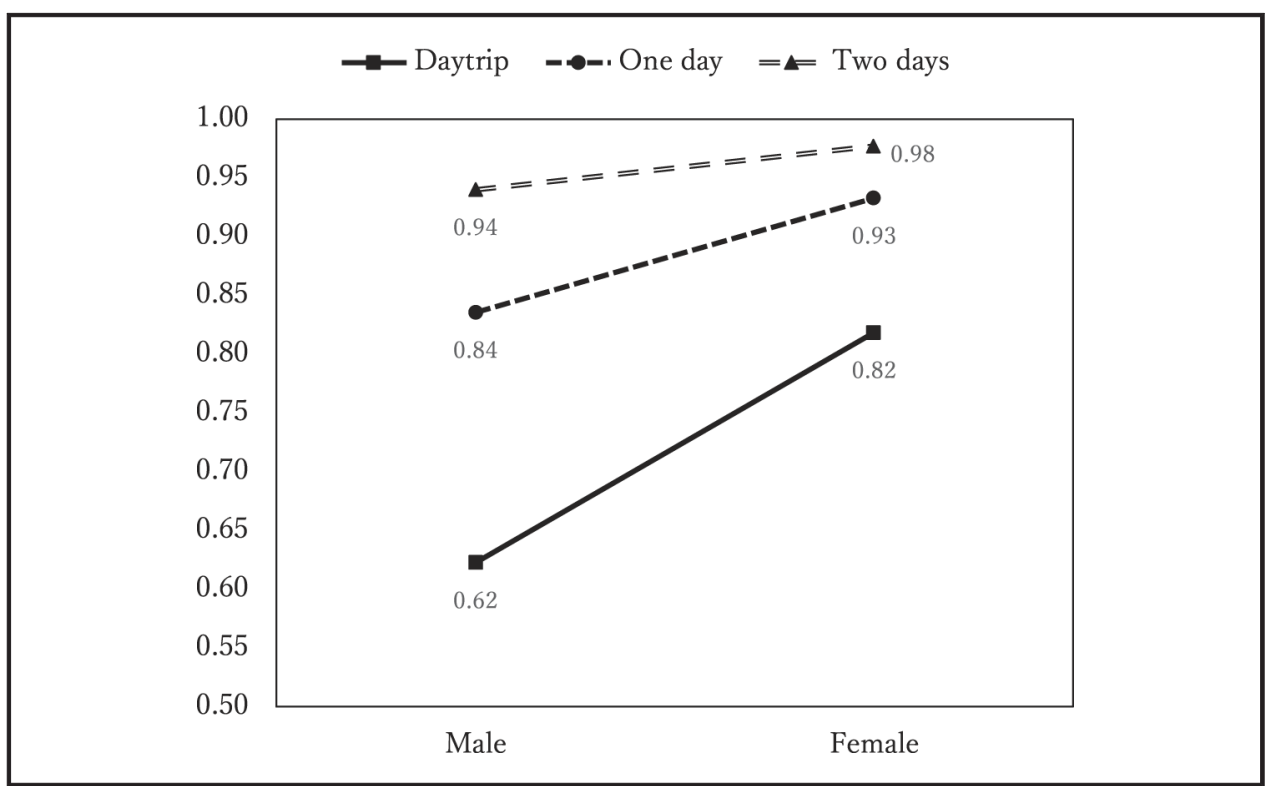

much higher than that of male visitors (20\% difference). In contrast, the gender effect on visitors' level of concern seems to be reduced when the length of stay increases. For those who anticipate staying two days or more, the difference in probability for being concerned between male and female visitors is modest. Moreover, the exceptionally high probability of respondents making an overnight stay in the park to be concerned - regardless of gender $(>84 \%)$ - hints at the deep concern about public health issues while travelling during the early phase of the pandemic. It also reveals the perceived additional risk of staying overnight at a hotel in the national park during the pandemic's early stage.

\section{Discussion}

The pandemic originated in Wuhan in 2019, and at the onset, China's East Asian neighbours, such as Korea and Japan, were also perceived as part of the epicentre due to geographical proximity and higher volumes of passenger traffic from infected areas. Exacerbated by geo-political tension, racial profiling, rhetoric and bigotry targeted China as the origin and initial epicentre of the virus (Jamal and Budke, 2020). In the United States and elsewhere, anti-Asian discrimination increased along with abuse and assaults (Chen et al., 2020a). Behind the bigotry, the negative imagery was perpetuated by evidence of an early surge in locally transmitted cases in South Korea that reported the first major cluster outside China in February 2020 (Choi et al., 2021). A high-profile media presence followed events on the Diamond Princess cruise ship in Japan, aboard which over 700 passengers from all over the world were ultimately diagnosed with the virus. In addition to their proximity to China, Northeast Asian metropolises, such as Seoul and Tokyo, were seen as vulnerable due to high densities of aging populations and widespread public transport use. East Asian source markets have also proved sensitive to past crises, as demonstrated by a reduction of over half the number of outbound Japanese travellers following the SARS epidemic (Cooper, 2006). But whereas SARS largely remained a regional cluster, COVID-19 cases have subsequently proliferated rapidly around the globe.

One year into the pandemic, the negative impacts have percolated every part of the planet, but policy responses have differed significantly at the country level. For instance, the United States tends to favour "scientific solutions", such as vaccines and antiviral medications, 
instead of rapidly implementing low-tech measures, such as wearing masks and washing hands (Gostin, 2006). After an inopportune start, East Asia has generally coped better than other regions due to certain swift and sweeping countermeasures in countries, such as Singapore, Taiwan and Vietnam (Rasmussen, 2020), partly due to experience accrued during the SARS epidemic in 2003 (La et al., 2020). Human rights have suffered, but some democracies have also responded proactively. For example, in South Korea, a range of innovative countermeasures were enforced early on, including mass testing (with a drivethrough variant), while existing legislation passed after the Middle East respiratory syndrome (MERS) outbreak in 2015 "gave the government authority to collect mobile phone, credit card and other data from those who test positive to reconstruct their recent whereabouts" to track, trace and quarantine infected persons (Normile, 2020). Such efforts are noteworthy as South Korean democracy has fewer authoritarian countermeasures and like Japan -has sought to avoid the economic devastation of an enforced lockdown, although the collection of data from phones or credit cards could still be deemed a breach of consumer privacy. This rationale symbolizes the way in which pandemic-era ethics enable prioritization of the common good over the protection of individual rights or autonomy (White et al., 2009). National-level public health policies can thus relegate the interests and rights of individuals to the common good (Gostin, 2006; Chia and Oyeniran, 2020) to the extent of violating human rights or international law (Meier et al., 2020).

Countries such as New Zealand have been held up as a paradigm of this "tough love" ethos, employing a more stringent set of policy responses at the start of the pandemic that hurt the tourism industry but curtailed catastrophic economic fallout later on (Mazey and Richardson, 2020). In single-party states such as Vietnam, a highly stringent policy response was also enforced relatively soon after the outbreak. International tourism was quickly shut down altogether, likewise domestic travel, although the latter was subsequently allowed to recommence. Although regional tourism later faced temporary shutdowns in August due to the resurgence of COVID-19 cases in the central provinces around Danang, tourism activities in Vietnam still regained more momentum when compared to laissez-faire European approaches that initially closed the borders more slowly or less comprehensively (La et al., 2020). This "isolationist" theory promotes stricter regulations on international travellers that could inadvertently function as viral vectors to domestic populations who would otherwise be at lower risk of infection (Wickramage et al., 2018).

Setting aside the authoritarian measures found in Vietnam, Singapore, etc., could generalizations of "collectivist" East Asian culture explain Japan's performance that boasted significantly fewer cases per capita than European peers, such as the United Kingdom, France and Germany? Japan had a relatively low stringency score 30 days after the first recorded case when the government responses were measured more broadly, including indicators such as mandatory closures of schools and workplaces or stay-athome requirements (An and Tang, 2020). Nonetheless, Japan was still relatively quick to close its borders to international travel (Figure 1). As the tourism market entered the initial phase of coronavirus containment measures, our survey at a ski resort in February 2020 captured a predominantly younger, domestic markets' perceptions of those travel restrictions. We reviewed Japanese ski and snowboarder perceptions of entry restrictions and social acceptance for the government-imposed COVID-19 countermeasures.

ANOVA tests revealed significant differences in social acceptance for countermeasures between more and less concerned visitors. Concerned visitors to Kuju were significantly more likely to agree with washing hands frequently $(M=3.7)$ or wearing a mask (3.4). These findings can be rationalized by their feasibility, low cost and widespread acceptance even before the pandemic. Personal hygiene and mask-wearing are persistently emphasized in Japanese public health messages along with other precautionary actions such as the so-called " 3 C's approach" that encourages people to avoid closed spaces with poor ventilation, crowded places with groups of people and close-contact settings, 
such as one-on-one conversations. This low-key alternative to more severe "lockdowns" at the local or national level reflects the reality that countermeasures "must be compatible with a polity's underlying culture" (An and Tang, 2020). Although our survey did not verify the actual compliance of visitors' behaviour with such public health messages (i.e. the per cent of visitors wearing a mask), personal observation and empirical evidence support the assumed social acceptance-compliance correlation.

Unsurprisingly, respondents' level of agreement with selective restrictions on foreigners from high-risk countries or areas with many cases of infection exceeded their acceptance to change or even cancel their own plans. The survey was conducted during the early stage when expectations were high that the pandemic could be locally contained. Restrictions on overseas travellers to the ski resort were viewed less favourably still, and despite the actual implementation of border controls on international visitors to Japan, this was deemed the least acceptable countermeasure by both more and less concerned segments in February 2020. According to the Oxford data, Japan's stringency index at the time of our survey was temporarily higher than the G20 cohorts, which could have raised the awareness of virus countermeasure and the level of concern amongst the general public. When faced with a pandemic, should policymakers take drastic top-down measures such as closing the borders or emphasize personal hygiene and self-regulation to contain the spread of the virus? Eventually, more concerned visitors will be more likely to shorten or cancel their travel plan, damaging the tourism industry. The policy response in Japan and elsewhere is influenced by the level of public concern linked to media visibility. Our findings thus hint at the dilemma between public health issues and tourism management. Closer collaboration is required "between tourism stakeholders and public health authorities. . to seek out correct scientific facts on the disease and take sensible precautions" (Jamal and Budke, 2020).

Findings also showed that female respondents in Kuju were more concerned about the pandemic than males, corroborating prior research that consistently finds women to be more risk-averse than men (Watson and McNaughton, 2007). This has been suggested as one of the explanatory factors behind a suspected reduced prevalence of COVID-19 amongst women (Cai, 2020). Prior research has indeed demonstrated that "females are less susceptible to acquire viral infections", although it is unclear if this due to psychological differences (e.g. risk aversion) or physiological ones such as immunity levels linked to different "susceptibility and progression of COVID-19 between male and female patients" (Kopel et al., 2020). However, Muurlink and Taylor-Robinson (2020) caution against simplistic gender-based divisions, presenting a range of cultural factors that could be confounding variables, including 1) religious customs or traditional clothing such as Muslim burka or niqab; 2) "distancing from men or separation from the broader workforce and community" and 3) data underrepresentation due to "reluctance to be attended by a male medical practitioner".

Moreover, the gender effect could have been diminished in our results if the visitor already had a predetermined plan to spend one night or more at a hotel in the national park (see Figure 4). Based on these results, future countermeasures and crisis management should also consider the risk aversion nature of visitors not only during the planning stage but also during the trip. However, although results suggested a perceived additional risk of staying overnight, it should be noted that the ski resort in our study is easily accessible from urban hubs such as Fukuoka and Kumamoto. According to a follow-up interview with the site managers, day trippers conventionally account for the bulk of winter sports visitors even prior to the pandemic (personal correspondence). This could reduce the non-response bias whereby more concerned visitors had already cancelled their trip or modified it. In European resorts, skiers tend to reside for several days or weeks, staying in dedicated accommodation such as hotels or chalets, dining out and partaking in apres-ski activities, but a higher proportion of ski resorts in Japan are designed primarily for day use, which could mitigate their risk of developing COVID clusters similar to those that occurred in 
Austria (Kreidl et al., 2020). However, if the risk-aversion effect holds true for hotels across the recreation market, it could have a devastating impact on the local economy. In fact, the decline in domestic travel was actively targeted by the Japanese government later on in 2020 via the launch of a controversial "Go To" campaign subsidizing up to 50\% of expenses, including accommodation and transport fees (Davies, 2020).

\section{Research limitations and implications}

Notwithstanding past epidemics like SARS and MERS, the tourism sector has shown remarkably steady growth since the latter half of the 20th century, with few exceptions. Consequently, travel restrictions and stringency indicators have tended to ease within the living memory of most of the world's population, so the current pandemic throws up a range of unprecedented challenges that require future research to offer innovative countermeasures that cut across research fields with theoretical and applied examples.

As this paper focussed specifically on policy and social acceptance among our Japanese ski and snowboard sample, essential indicators such as the COVID-19 fatality rate or excess mortality had to be excluded from the scope of this research. However as the pandemic continues to unfold, the proportion of asymptomatic or mild cases - and therefore the prevalence of COVID-19 - remains uncertain, so there is an urgent need to identify both the rate and the "infectivity and transmissibility period" (Miyamae et al., 2020) in order to establish quarantine benchmarks for travel restrictions (Chen et al., 2020b). In addition, the necessity of travel bans must be weighed against less restrictive alternatives including Japan's "3 C's approach" that encourages people to avoid closed spaces with poor ventilation, crowded places with groups of people and close-contact settings, such as oneon-one conversations (Meier et al., 2020).

In addition, three limitations are acknowledged. Our ski resort survey was conducted at an early stage of the COVID-19 pandemic resulting in considerable uncertainty as reflected in respondents' perceptions. However, the originality of this paper also derived from a primary dataset of domestic opinion collected during the onset of the pandemic that uncovers predictors for social acceptance. This could have implications for future policy-making in the case of further "waves" of COVID-19 infectiousness or in the case of other pandemics that occur in the future. Besides, our primary data are triangulated by macro-level evidence at the national and G20 level via the OxCGRT dataset displayed in Figure 1. This compared Japan against the G20 cohorts, however, one of the G20 members was listed as EU, which was not available as an aggregate dataset (although France and Germany were included). Hence Japan's stringency policies were ultimately compared against 18 peer nations. In addition, this was a "real-time" assessment of the virus' impact, and given the rapid rate at which the pandemic has evolved, certain aspects of our analysis may be out of date or incompatible for future research (Baum and Hai, 2020; Jamal and Budke, 2020).

\section{Conclusion}

As of 17 February 2021, the human cost of COVID-19 includes over 108.9 million global cases and $2.4 \mathrm{~m}$ deaths (Financial Times, 2021). The pandemic has also caused enormous economic and social dislocation. Governments must weigh decisions about travel restriction policies' stringency against other concerns, such as the negative socioeconomic impacts and invasions of human rights. At the onset of the pandemic, considerable uncertainties still surrounded the most effective form of countermeasures, raising questions over social acceptance and compliance. Concerned and non-concerned visitors to Kuju displayed significantly different attitudes towards washing hands, wearing a mask and modifying or cancelling their own travel plans. These findings hint at the dilemma facing converging public health and tourism policies. Travel restrictions and quarantines 
impact individuals' freedom, amounting to a fundamental violation of international law (Meier et al., 2020). Threats to human rights remain an ongoing issue as anxiety related to the ongoing pandemic manifests itself in discriminatory or xenophobic policies implemented in spite of empirical evidence (Chia and Oyeniran, 2020).

In the struggle to coordinate a holistic response to the pandemic, various sub-optimal or openly intolerant policies have emerged as stopgaps. Although Japan has avoided the local lockdowns implemented in many OECD countries, a blanket ban for much of 2020 on (re)-entry for foreigners -including permanent residents - belies the tolerant response of our ski survey. Japan's travel ban seems especially heavy-handed in comparison to a smart phone application developed by dexterous South Korean authorities allowing international travellers to enter provided "they agree to comply with the quarantine rules and self-report" (Choi et al., 2021). Morris-Suzuki (2015) warns that prejudice in Japan tends to be "situated within a nexus of interrelated forms of discrimination and marginalization". This is relevant as the debate over "inclusiveness" seems likely to be extended to vaccines in the near future, with uncertainty over the eligibility of permanent residents (PRs) or other foreign residents to be inoculated. In short, it is not known if Japan will "provide migrant groups with the same level of protection that they offer their own citizens" (Thompson, 2013; Wickramage et al., 2018). The indiscriminate lumping together of PRs with tourists and other short-term visitors poses serious questions for the Japanese government's stated goal of creating a more diverse, inclusive and equitable society (Osumi, 2020). Meanwhile, the restrictions on international travellers are likely to spark further debate during the controversial Olympic Games, re-scheduled for July 2021. It is worth re-emphasizing that drastic border measures scored lowest in our survey's social acceptance. Due diligence must be exercised to curtail the pandemic's ability to test the limits of a tolerant global society and undermine human rights in the name of public health.

\section{References}

An, B.Y. and Tang, S.-Y. (2020), "Lessons from COVID-19 responses in East Asia: institutional infrastructure and enduring policy instruments", The American Review of Public Administration, Vol. 50 Nos 6/7, pp. 790-800.

Anzai, A., Kobayashi, T., Linton, N.M., Kinoshita, R., Hayashi, K., Suzuki, A., Yang, Y., Jung, S.-m., Miyama, T. and Akhmetzhanov, A.R. (2020), "Assessing the impact of reduced travel on exportation dynamics of novel coronavirus infection (COVID-19)", Journal of Clinical Medicine, Vol. 9 No. 2, p. 601.

Baum, T. and Hai, N.T.T. (2020), "Hospitality, tourism, human rights and the impact of COVID-19", International Journal of Contemporary Hospitality Management, Vol. 32 No. 7, pp. 2397-2407.

Brug, J., Aro, A.R., Oenema, A., De Zwart, O., Richardus, J.H. and Bishop, G.D. (2004), "SARS risk perception, knowledge, precautions, and information sources, The Netherlands", Emerging Infectious Diseases, Vol. 10 No. 8, p. 1486.

Cai, H. (2020), "Sex difference and smoking predisposition in patients with COVID-19", The Lancet Respiratory Medicine, Vol. 8 No. 4, p. e20.

Chen, J.A., Zhang, E. and Liu, C.H. (2020a), "Potential impact of COVID-19-related racial discrimination on the health of Asian Americans", American Journal of Public Health, Vol. 110 No. 11, pp. 1624-1627.

Chen, S., Zhang, Z., Yang, J., Wang, J., Zhai, X., Bärnighausen, T. and Wang, C. (2020b), "Fangcang shelter hospitals: a novel concept for responding to public health emergencies", The Lancet, Vol. 395 No. 10232, pp. 1305-1314.

Chia, T. and Oyeniran, O.I. (2020), "Human health versus human rights: an emerging ethical dilemma arising from coronavirus disease pandemic", Ethics, Medicine and Public Health, Vol. 14, p. 100511.

Choi, J., Lee, S. and Jamal, T. (2021), "Smart Korea: governance for smart justice during a global pandemic", Journal of Sustainable Tourism, Vol. 29 Nos 2/3, pp. 540-549.

Cooper, M. (2006), "Japanese tourism and the SARS epidemic of 2003", Journal of Travel and Tourism Marketing, Vol. 19 Nos 2/3, pp. 117-131. 
Davies, R.E.T. (2020), Breaking Down Japan's Go to Travel Campaign, The Japan Times, Tokyo, 18 October 2020.

Financial Times (2021), Coronavirus Tracker: The Latest Figures as Countries Fight the Covid-19 Resurgence.

Gharzai, L.A., Beeler, W.H. and Jagsi, R. (2020), "Playing into stereotypes: engaging millennials and generation Z in the COVID-19 pandemic response", Advances in Radiation Oncology, Vol. 5 No. 4 , pp. 679-681.

Gostin, L. (2006), "Public health strategies for pandemic influenza: ethics and the law", The Journal of the American Medical Association, Vol. 295 No. 14, pp. 1700-1704.

Hale, T., Petherick, A., Phillips, T. and Webster, S. (2020), Variation in Government Responses to COVID19, Blavatnik School of Government, Working Paper, Vol. 31.

Jamal, T. and Budke, C. (2020), "Tourism in a world with pandemics: local-global responsibility and action”, Journal of Tourism Futures, Vol. 6 No. 2, pp. 181-188.

Kopel, J., Perisetti, A., Roghani, A., Aziz, M., Gajendran, M. and Goyal, H. (2020), "Racial and genderbased differences in COVID-19", Frontiers in Public Health, Vol. 8, p. 418.

Kreidl, P., Schmid, D., Maritschnik, S., Richter, L., Borena, W., Genger, J.-W., Popa, A., Penz, T., Bock, C. and Bergthaler, A. (2020), "Emergence of coronavirus disease 2019 (COVID-19) in Austria", Wiener Klinische Wochenschrift, Vol. 132 No. 21, pp. 645-652.

La, V.-P., Pham, T.-H., Ho, M.-T., Nguyen, M.-H., P Nguyen, K.-L., Vuong, T.-T., Tran, T., Khuc, Q., Ho, M.T. and Vuong, Q.-H. (2020), "Policy response, social media and science journalism for the sustainability of the public health system amid the COVID-19 outbreak: the vietnam lessons", Sustainability, Vol. 12 No. 7, p. 2931.

Mallapaty, S. (2020), "What the cruise-ship outbreaks reveal about COVID-19", Nature, Vol. 580 No. 7801 , p. 18.

Mazey, S. and Richardson, J. (2020), "Lesson-drawing from New Zealand and covid-19: the need for anticipatory policy making", The Political Quarterly, Vol. 91, pp. 561-570.

Meier, B.M., Habibi, R. and Yang, Y.T. (2020), "Travel restrictions violate international law", Science, Vol. 367 No. 6485 , p. 1436.

Miyamae, Y., Hayashi, T., Yonezawa, H., Fujihara, J., Matsumoto, Y., Ito, T., Tsubota, T. and Ishii, K. (2020), "Duration of viral shedding in asymptomatic or mild cases of novel coronavirus disease 2019 (COVID-19) from a cruise ship: a single-hospital experience in Tokyo, Japan", International Journal of Infectious Diseases, Vol. 97, pp. 293-295.

Morris-Suzuki, T. (2015), "Beyond racism: semi-citizenship and marginality in modern Japan", Japanese Studies, Vol. 35 No. 1, pp. 67-84.

Muurlink, O.T. and Taylor-Robinson, A. (2020), "COVID-19: cultural predictors of gender differences in global prevalence patterns", Frontiers in Public Health, Vol. 8, p. 174.

Normile, D. (2020), Coronavirus Cases Have Dropped Sharply in South Korea. What's the Secret to its Success?, 5th April 2021, available at: www.sciencemag.org/news/2020/03/coronavirus-cases-havedropped-sharply-south-korea-whats-secret-its-success

Osumi, M. (2020), Foreign Residents Stranded Abroad by Japan's Coronavirus Controls, Japan Times, Tokyo, 19th May 2020.

PennState (n.d.), Lesson 6: Logistic Regression, 21 February 2021, available at: https://online.stat.psu. edu/stat504/lesson/6

Rasmussen, A.F. (2020), Taiwan Has Been Shut Out of Global Health Discussions. Its Participation Could Have Saved Lives.

Thompson, L. (2013), "Protection of migrants' rights and state sovereignty", UN Chronicle, Vol. 50 No. 3 , pp. 8-11.

UNEP-WCMC (2020), Protected Area Profile for Aso kuju from the World Database of Protected Areas, 4th September 2020, available at: www. protectedplanet.net/en

Vuong, Q.H. (2015), “Be rich or don’t be sick: estimating Vietnamese patients' risk of falling into destitution", SpringerPlus, Vol. 4 No. 1, p. 529. 
Vuong, Q.-H., Ho, T.-M., Nguyen, H.-K. and Vuong, T.-T. (2018), "Healthcare consumers' sensitivity to costs: a reflection on behavioural economics from an emerging market", Palgrave Communications, Vol. 4 No. 1, p. 70.

Watson, J. and McNaughton, M. (2007), "Gender differences in risk aversion and expected retirement benefits”, Financial Analysts Journal, Vol. 63 No. 4, pp. 52-62.

White, D.B., Katz, M.H., Luce, J.M. and Lo, B. (2009), "Who should receive life support during a public health emergency? Using ethical principles to improve allocation decisions", Annals of Internal Medicine, Vol. 150 No. 2, pp. 132-138.

WHO (2020), A Joint Statement on Tourism and COVID-19 - UNWTO and WHO Call for Responsibility and Coordination, 5th September 2020, available at: www.who.int/news/item/27-02-2020-a-joint-statementon-tourism-and-covid-19-unwto-and-who-call-for-responsibility-and-coordination

Wickramage, K., Gostin, L.O., Friedman, E., Prakongsai, P., Suphanchaimat, R., Hui, C., Duigan, P., Barragan, E. and Harper, D.R. (2018), "Missing: where are the migrants in pandemic influenza preparedness plans?", Health Human Rights, Vol. 20 No. 1, p. 251.

Zenker, S. and Kock, F. (2020), "The coronavirus pandemic - a critical discussion of a tourism research agenda”, Tourism Management, Vol. 81, p. 104164.

\section{Further reading}

Faulkner, B. (2001), "Towards a framework for tourism disaster management", Tourism Management, Vol. 22 No. 2, pp. 135-147.

Ritchie, B.W. (2004), "Chaos, crisis, and disaster: a strategic approach to crisis management in the tourism industry", Tourism Management, Vol. 25 No. 6, pp. 669-683.

\section{Corresponding author}

Thomas Jones can be contacted at: 110054tj@apu.ac.jp

For instructions on how to order reprints of this article, please visit our website: www.emeraldgrouppublishing.com/licensing/reprints.htm

Or contact us for further details: permissions@emeraldinsight.com 